\title{
Effect of resveratrol on diabetic neuropathy in wistar albino rats
}

\author{
Smita Das $^{1 *}$, Jayanti Prava Behera ${ }^{2}$, Y. Rojaramani ${ }^{3}$, Rashmi Ranjan Mohanty ${ }^{4}$
}

\author{
${ }^{1}$ Department of Pharmacology, IMS \& SUM Hospital, SOA (Deemed to be University), Bhubaneswar, Odisha, India \\ ${ }^{2}$ Department of Pharmacology, Bhima Bhoi Medical College, Balangir, Odisha, India \\ ${ }^{3}$ Department of Pharmacology, MKCG Medical College, Berhampur, Odisha, India \\ ${ }^{4}$ Department of Medicine, AIIMS, Bhubaneswar, Odisha, India
}

Received: 22 November 2019

Revised: 11 December 2019

Accepted: 12 December 2019

\section{*Correspondence:}

Dr. Smita Das,

Email: drsmitadasmohanty@gmail.com

Copyright: (C) the author(s), publisher and licensee Medip Academy. This is an open-access article distributed under the terms of the Creative Commons Attribution Non-Commercial License, which permits unrestricted non-commercial use, distribution, and reproduction in any medium, provided the original work is properly cited.

\begin{abstract}
Background: Type 2 diabetes mellitus (DM) is a common chronic disease with increasing prevalence worldwide. Prolonged uncontrolled hyperglycemia, dyslipidemia are major risk factor for its complication like neuropathy. Since there is no definite treatment for diabetic neuropathy, this study aims to evaluate the effect of resveratrol on diabetic neuropathy in high fat diet with low dose streptozotocin induced type-2 DM model in wistar albino rats.

Methods: First type 2 diabetic rat model was established. Wistar albino rats, fed with high-fat diet (HFD) rendered diabetic with streptozotocin, were divided into 6 groups, disease control (DC) treated with vehicle, standard control (SC) which received metformin, test groups treated with 5,10 , and $20 \mathrm{mg} / \mathrm{kg} \mathrm{b.w}$. of resveratrol and combination of half dose of metformin and resveratrol $(10 \mathrm{mg} / \mathrm{kg}$ ) (TC). A group of six normal animals served as normal control (NC), another six as HFD control. Fasting plasma glucose, lipid profile were measured one week after induction of diabetes. The animals were then treated orally for 2 weeks after which the same parameters were repeated. Behavioral biomarkers for neuropathy are measured in 4 weeks and 6 weeks of treatment. The in-vivo results were analyzed by one way ANOVA followed by Tukey's multiple comparison test for biochemical parameters and Kruskal Wallis test followed by Dun's multiple comparison test for behavioral biomarkers.

Results: Increase in fasting plasma glucose (FPG), deranged lipid profile, increased neuropathy in DC compared to NC, HFD control while a significant decrease in FBG, improved pain behavior with SC, test groups $(\mathrm{p}<0.05)$ as compared to the DC group.
\end{abstract}

Conclusions: Resveratrol prevents diabetic neuropathy.

Keywords: Diabetes, Resveratrol, Diabetic neuropathy

\section{INTRODUCTION}

International Diabetes Federation has estimated that 415 million people have been diagnosed with diabetes mellitus (DM) worldwide and a rise of up to 640 million by 2040 being anticipated. ${ }^{1}$ Diabetic neuropathy (DN) is one of the important complications of diabetes mellitus resulting in a great deal of morbidity, increased mortality and impaired quality of life. The prevalence of diabetic neuropathy is increasing up to $30 \%$ in Indian population. ${ }^{2}$
In US, DN is the leading cause of diabetes related hospital admissions and non-traumatic amputations. ${ }^{3}$ Peripheral diabetic neuropathy, untreated for a longer period, may lead to loss of neuronal reflexes and deformities that may progress to gangrene. In about $80 \%$ cases of DN amputations follow a foot ulcer or injury. ${ }^{4}$

Diabetic neuropathy is characterized by complex changes in functional and sensorimotor parameters. There is no definitive treatment for DN at present. Only few 
nonspecific drugs like tricyclic antidepressants, SNRIs, anticonvulsants, opioids and topical capsaicin have been tried in the management of painful neuropathy. Out of which duloxetine and pregabalin have been approved by the US FDA. ${ }^{5}$ But the cost and side effects of these drugs limit their use. Epalrestat, the only aldose reductase inhibitor, is approved and marketed in Japan. As free radicals play an important role in pathophysiology of DN, the drugs with antihyperglycemic and antioxidant properties will be more beneficial in this condition. ${ }^{6}$ Though there are various approaches are available to treat diabetes and prevent its secondary complications, herbal medications may be used as an alternative therapy as these are well tolerated.

Resveratrol is a plant-derived polyphenolic phytoalexin from grape skin and seeds of groundnuts, peanuts and several other plants that is produced by certain enzyme when under attack by infectious agents. Grape skin provides a relatively high concentration of resveratrol. ${ }^{7}$ Resveratrol has inhibitory effects on free radicals accounting for antioxidant properties, also blood sugar lowering effect, anti-inflammatory, cardio protective effect in experimental animal models. ${ }^{8}$

\section{Aims and objectives}

In this context, the present study was undertaken to evaluate the effect of resveratrol on diabetic neuropathy in high fat diet with low dose streptozotocin induced type-2 DM model in wistar albino rats.

\section{METHODS}

Wistar albino rats of either sex weighing between 100$150 \mathrm{~g}$ were procured from National Institute of Nutrition, Hyderabad, India. They were housed in clean polypropylene cages (four rats per cage), maintained under controlled room temperature $\left(25 \pm 1^{\circ} \mathrm{C}\right)$ and with relative humidity of $45-55 \%$ under $12: 12 \mathrm{hr}$ light and dark cycle in the central animal house. They were provided with standard lab diet and water ad libitum and kept for 1 week to acclimatize with the laboratory condition before starting the experiment. Prior to the study, the study protocol was approved by I.A.E.C, M.K.C.G. Medical College, Berhampur. The study was carried out as per CPCSEA guidelines.

\section{Study design}

54 wistar albino rats were grouped randomly into 9 groups and distributed 6 in each as follows:

\section{Control groups}

Gr-I: Normal pellet diet and distilled water PO.

Gr-II: Normal pellet diet and dimethyl sulfoxide (DMSO) PO.

Gr-III: High fat diet (HFD) and DMSO PO.

\section{Disease control}

$G r-I V$ : HFD and oral DMSO after induction of diabetes.

\section{Test groups}

$G r$-V-VII: Resveratrol in $5,10,20 \mathrm{mg} / \mathrm{kg}$ orally for 2 weeks, after induction of diabetes.

\section{Standard group}

Gr-VIII: Metformin $(0.5 \mathrm{gm} / \mathrm{kg})$ orally for 2 weeks after induction of diabetes

\section{Combination of test and standard}

Gr-IX: Minimum effective dose of resveratrol $(10 \mathrm{mg} / \mathrm{kg}$ ) and half dose of metformin $(250 \mathrm{mg} / \mathrm{kg})$ orally for 2 weeks after induction of diabetes.

\section{Procedure}

The test drug resveratrol was obtained from InvivoGen, streptozotocin from Himedia Lab. and high fat diet was prepared in the laboratory. ${ }^{9}$ The doses of standard and test drugs were selected from published literature. ${ }^{10}$ The test drug resveratrol was dissolved with DMSO before administration whereas distilled water served as vehicle for standard drug metformin.

Preparation of HFD: High fat diet was prepared by adding excess of coconut oil to normal diet so as to provide $42 \%$ of total calories from the fat source. ${ }^{9}$

Preparation of stock solution resveratrol: To obtain a 20 $\mathrm{mg} / \mathrm{ml}$ stock solution, $250 \mu \mathrm{l}$ DMSO was added to $5 \mathrm{mg}$ resveratrol powder. Solution was then vortexed until complete solubilization, aliquoted and stored at $4{ }^{0} \mathrm{C}$. Required dose was obtained by dilution with distilled water as per the instruction given by the product manufacturer.

\section{Induction of diabetes}

Diabetes was induced in HFD fed wistar albino rats fasted overnight by I.P injection of single dose of freshly prepared solution of streptozotocin $(40 \mathrm{mg} / \mathrm{kg})$ which was made by dissolving with $0.1 \mathrm{M}$ citrate buffer solution $(\mathrm{pH}$ 4.5) containing $0.9 \% \mathrm{NaCl}$ after 2 weeks of high fat diet. ${ }^{11}$ To avoid an early fatal hypoglycemia $5 \%$ glucose solution was fed on 1st day of streptozotocin administration to all rats. The rats having fasting glucose level $\geq 200 \mathrm{mg} / \mathrm{dl}$ after $48 \mathrm{hrs}$ of administration of streptozotocin (STZ) and persistent after $7^{\text {th }}$ day after administration of STZ were considered diabetic and included in the study groups. ${ }^{12}$ Diabetic neuropathy developed after 4 weeks of induction of diabetes. 


\section{Estimation of biochemical parameters}

After 12 hour fasting, about $3 \mathrm{ml}$ of blood was collected in a sterilized test tube containing ethylenediamine-tetra acetic acid through retro-orbital puncture under light ether anesthesia. Assay of fasting plasma glucose (FPG) by glucose oxidase or peroxidase method, plasma cholesterol by cholesterol oxidase or phenol and aminophenazone (PAP) method, triglyceride by glycerol3-phosphate oxidase or PAP method and high-density lipoproteins (HDL) by Peg precipitation method were estimated by using commercially available kits. The lowdensity lipoproteins (LDL) cholesterol was calculated from the formula of Friedwald et al as given below: ${ }^{13}$

LDL-C = Total cholesterol - [HDL+VLDL]

Where VLDL $=$ Triglyceride $/ 5$

\section{Evaluation of biomarkers of neuropathy}

Behavioral biomarker: Assessment of neuropathic pain was done by thermal method which include tail flick test (tail immersion test) for hot allodynia and acetone induced cold allodynia and chemical method by formalin test. $^{14-16}$

Functional biomarkers: Gastroparesis assessed by charcoal meal test. ${ }^{17}$

\section{Statistical analysis}

The data obtained from parametric tests of this study like FPG, lipid profile were analyzed by one way ANOVA followed by Tukey's multiple comparison test and Kruskal wallis test followed by Dun's multiple comparison test for behavioral biomarkers.

The $\mathrm{p}$ values less than 0.05 was considered statistically significant. SPSS was used for data analysis in a personal computer.

\section{RESULTS}

The mean FPG level and lipid profile in HFD or streptozotocin induced diabetic rats treated with resveratrol at doses $10 \mathrm{mg} / \mathrm{kg}$ and $20 \mathrm{mg} / \mathrm{kg}$ were significantly decreased in comparison to that of disease control (DC) which is comparable to standard treated groups. But $5 \mathrm{mg} / \mathrm{kg}$ dose of resveratrol does not produce any significant effect on hyperglycemia. Minimum effective dose of resveratrol $(10 \mathrm{mg} / \mathrm{kg})$ with half dose of metformin $(250 \mathrm{mg} / \mathrm{kg})$ produced significant decrease in FPG and improvement in lipid profile compared with that of disease control.

\section{Behavioural biomarkers}

\section{Assessment of neuropathic pain}

In Table 1 it is observed that tail flick latency (TFL) is significantly decreased in disease control at 4 weeks i.e.
$2.21 \pm 0.13 \mathrm{sec}$ in comparison with normal control $(2.95 \pm 0.09 \mathrm{sec})$ showing development of hyperalgesia. Groups that received resveratrol $10 \mathrm{mg} / \mathrm{kg}$ and $20 \mathrm{mg} / \mathrm{kg}$ produced significant increase in TFL i.e 2.99 \pm 0.16 and $3.33 \pm 0.13 \mathrm{sec}$ respectively at 4 weeks which are similar to metformin treated group $(2.96 \pm 0.05)$ and not significantly different from normal control. But at 6 weeks interval the TFL $(4.97 \pm 0.20 \mathrm{sec})$ which is significantly increased in disease control in comparison to control received DMSO due to development of hypoalgesia, a feature of neuropathy. Resveratrol treated groups at 10 and 20 $\mathrm{mg} / \mathrm{kg}$ doses significantly decreased the TFL i.e. $3.7 \pm 0.14$ and $3 \pm 0.07 \mathrm{sec}$, respectively compared with that of control group at 6 weeks which is similar with metformin treated group i.e. $(3.2 \pm 0.1 \mathrm{sec})$ The combined effect of resveratrol and metformin also produced significant reversal of TFL and is not significantly different from metformin alone at both the time points.

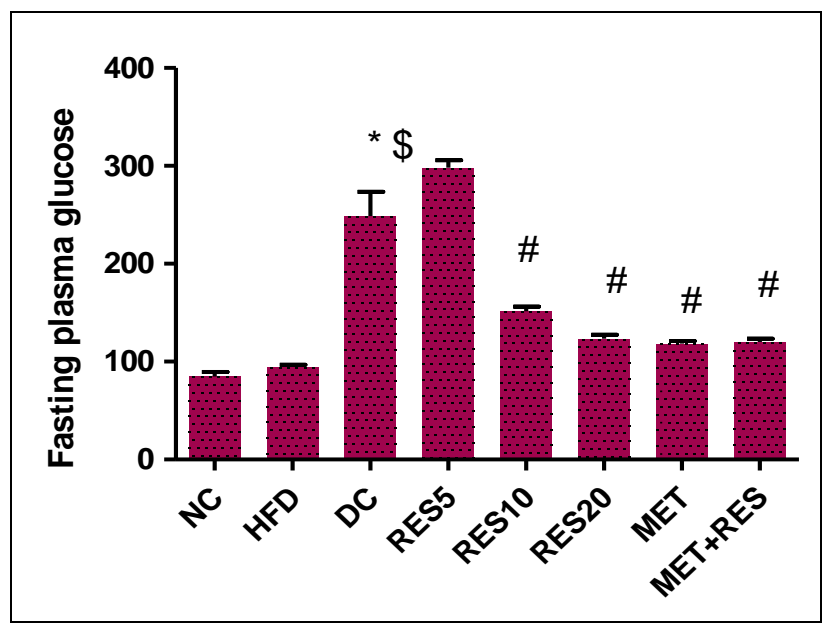

Figure 1: Effect of resveratrol on FPG concentrations in HFD and STZ induced diabetic rats $(n=6)$.

Data expressed as Mean \pm SE, Resv-resveratrol, Met- metformin, ${ }^{*} \mathrm{p}<0.05$ (NC vs. DC), $\$ \mathrm{p}<0.05$ (HFD vs. DC), \#p<0.05(DC vs. treatment groups).

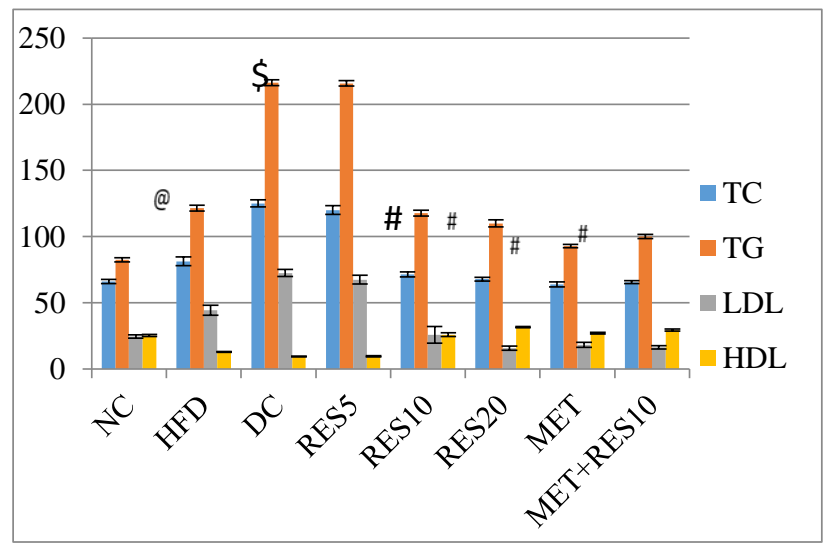

Figure 2: Effect of resveratrol on plasma lipid profile in HFD and STZ induced diabetic rats $(n=6)$.

Data are expressed as Mean \pm SEM, Resv-resveratrol, Metmetformin, @ ( p<0.05) (NC vs. HFD), *(p<0.001) (NC vs. DC), $\$ \mathrm{p}<0.05$ (HFD vs. DC), \#(p<0.05) (DC vs. treatment groups). 
Table 1: Effect of drugs on TFL in tail immersion test in diabetic rats at 4 weeks and 6 weeks interval $(n=6)$.

\begin{tabular}{|c|c|c|c|}
\hline \multirow{2}{*}{ Groups } & & \multicolumn{2}{|c|}{ TFL (in sec) } \\
\hline & & \multirow{2}{*}{$\begin{array}{l}4 \text { weeks } \\
2.95 \pm \\
0.09\end{array}$} & \multirow{2}{*}{$\begin{array}{l}6 \text { weeks } \\
2.96 \pm \\
0.07\end{array}$} \\
\hline Gr-II & Control (DMSO) & & \\
\hline Gr-III & HFD control+ DMSO & $\begin{array}{l}3.37 \pm \\
0.15\end{array}$ & $\begin{array}{l}3.23 \pm \\
0.14\end{array}$ \\
\hline Gr-IV & $\begin{array}{l}\mathrm{DC}(\mathrm{HFD}+\mathrm{STZ}-40 \\
\mathrm{mg} / \mathrm{kg})+\mathrm{DMSO}\end{array}$ & $\begin{array}{l}2.21 \pm \\
0.13^{*}\end{array}$ & $\begin{array}{l}4.97 \pm \\
0.20^{*}\end{array}$ \\
\hline Gr-V & $\begin{array}{l}\text { Diabetic+Resv ( } 5 \\
\mathrm{mg} / \mathrm{kg})\end{array}$ & $\begin{array}{l}2.23 \pm \\
0.14\end{array}$ & $\begin{array}{l}4.8 \pm \\
0.16\end{array}$ \\
\hline Gr-VI & $\begin{array}{l}\text { Diabetic+Resv (10 } \\
\mathrm{mg} / \mathrm{kg})\end{array}$ & $\begin{array}{l}2.99 \pm \\
0.16^{@}\end{array}$ & $\begin{array}{l}3.73 \pm \\
0.14^{@}\end{array}$ \\
\hline Gr-VII & $\begin{array}{l}\text { Diabetic+Resv ( } 20 \\
\mathrm{mg} / \mathrm{kg})\end{array}$ & $\begin{array}{l}3.33 \pm \\
0.13^{@}\end{array}$ & $\begin{array}{l}3 \pm \\
0.07^{@}\end{array}$ \\
\hline Gr-VIII & $\begin{array}{l}\text { Diabetic+Met (500 } \\
\mathrm{mg} / \mathrm{kg})\end{array}$ & $\begin{array}{l}2.96 \pm \\
0.05^{@}\end{array}$ & $\begin{array}{l}3.2 \pm \\
0.1^{@}\end{array}$ \\
\hline Gr-IX & $\begin{array}{l}\text { Diabetic+(Resv } 10 \\
\mathrm{mg} / \mathrm{kg}+\text { Met } 250 \mathrm{mg} / \mathrm{kg})\end{array}$ & $\begin{array}{l}3.0 \pm \\
0.06^{@}\end{array}$ & $\begin{array}{l}2.9 \pm \\
0.08^{@}\end{array}$ \\
\hline
\end{tabular}

Data expressed as Mean \pm SEM, Resv-resveratrol, Metmetformin, ${ }^{*} \mathrm{p}<0.05$ (control vs. diabetic group), ${ }^{\circledR} \mathrm{p}<0.05$ (diabetic group vs. treatment group).

\section{Assessment of acetone induced cold allodynia}

It was observed from Table 2, that cumulative score is significantly increased in disease control i.e. $11.17 \pm 0.40$ in comparison with normal control received DMSO i.e. $0.67 \pm 0.21$. Groups received resveratrol $5 \mathrm{mg} / \mathrm{kg}$ and 10 $\mathrm{mg} / \mathrm{kg}$ produced decrease in cumulative score i.e. $9.67 \pm 0.21$ and $5.17 \pm 0.48$ respectively in comparison to disease control but it is significantly more than that of normal control, but with $20 \mathrm{mg} / \mathrm{kg}$ dose, significantly decreased i.e. $2.33 \pm 0.42$ in comparison to disease control which is similar to metformin treated group and not significantly different from normal control.

It is observed from the Table 3, that cumulative score is not significantly different in disease control i.e. $0.5 \pm 0.21$ in comparison with normal control i.e. 0.67 \pm 0.21 . Groups received drugs also did not produced significant change in cumulative score than that of disease control.

Table 2: Effect of drugs on mean score of paw acetone test at 4 week interval (hyperalgesia) $(n=6)$.

\begin{tabular}{|c|c|c|c|c|c|c|}
\hline \multirow{3}{*}{ Groups } & & \multicolumn{4}{|c|}{ Mean scores } & \multirow{3}{*}{$\begin{array}{l}\text { Cumulative } \\
\text { score }\end{array}$} \\
\hline & & \multicolumn{2}{|c|}{ RT PAW } & \multicolumn{2}{|c|}{ LT PAW } & \\
\hline & & 0 min & $5 \mathrm{~min}$ & 0 min & $5 \mathrm{~min}$ & \\
\hline Gr-II & Control (DMSO) & 0.17 & 0.17 & 0.17 & 0.17 & $0.67 \pm 0.21$ \\
\hline Gr-III & HFD control+DMSO & 0.17 & 0.17 & 0.17 & 0.17 & $0.67 \pm 0.21$ \\
\hline Gr-IV & DC(HFD+STZ- $40 \mathrm{mg} / \mathrm{kg})+\mathrm{DMSO}$ & 3 & 2.6 & 2.6 & 2.8 & $11.17 \pm 0.40 *$ \\
\hline Gr-V & Diabetic+Resv $(5 \mathrm{mg} / \mathrm{kg})$ & 2.5 & 2.3 & 2.5 & 1.17 & $9.67 \pm 0.21$ \\
\hline Gr-VI & Diabetic+Resv $(10 \mathrm{mg} / \mathrm{kg})$ & 1.67 & 1.17 & 1.3 & 1 & $5.17 \pm 0.48 \#$ \\
\hline Gr-VII & Diabetic+Resv (20 mg/kg) & 0.67 & 0.5 & 0.5 & 0.67 & $2.33 \pm 0.42 \#$ \\
\hline Gr-VIII & Diabetic+Met $(500 \mathrm{mg} / \mathrm{kg})$ & 0.67 & 0.5 & 0.33 & 0.33 & $1.83 \pm 0.30 \#$ \\
\hline Gr-IX & Diabetic+(Resv 10 mg/kg+Met 250 mg/kg) & 0.3 & 0.3 & 0.3 & 0.67 & $1.67 \pm 0.21 \#$ \\
\hline
\end{tabular}

Data expressed as Mean \pm SEM, Resv-resveratrol, Met- metformin, ${ }^{*} \mathrm{p}<0.05$ (control vs. diabetic group), ${ }^{\#} \mathrm{p}<0.05$ (diabetic group vs. treatment groups).

Table 3: Effect of drugs on mean score of paw acetone test at 6 weeks interval (hypoalgesia) (n=6).

\begin{tabular}{|c|c|c|c|c|c|c|}
\hline \multirow{3}{*}{ Groups } & & \multicolumn{4}{|c|}{ Mean scores } & \multirow{3}{*}{$\begin{array}{l}\text { Cumulative } \\
\text { score }\end{array}$} \\
\hline & & \multicolumn{2}{|c|}{ RT paw } & \multicolumn{2}{|c|}{ LT paw } & \\
\hline & & 0 min & $5 \mathrm{~min}$ & $0 \mathrm{~min}$ & $5 \mathrm{~min}$ & \\
\hline Gr-II & Control (DMSO) & 0.17 & 0.17 & 0.17 & 0.17 & $0.67 \pm 0.21$ \\
\hline Gr-III & HFD control + DMSO & 0.17 & 0.17 & 0.17 & 0.17 & $0.67 \pm 0.21$ \\
\hline Gr-IV & DC (HFD+STZ- 40 mg/kg)+ DMSO & 0 & 0.16 & 0.16 & 0.16 & $0.5 \pm 0.21$ \\
\hline Gr-V & Diabetic+Resv (5 mg/kg) & 0.16 & 0.16 & 0.16 & 0.33 & $0.83 \pm 0.16$ \\
\hline Gr-VI & Diabetic+Resv (10 mg/kg) & 0.33 & 0.33 & 0.33 & 0.33 & $1.33 \pm 0.21$ \\
\hline Gr-VII & Diabetic+Resv (20 mg/kg) & 0.33 & 0.33 & 0.16 & 0.33 & $1.16 \pm 0.16$ \\
\hline Gr-VIII & Diabetic+Met $(500 \mathrm{mg} / \mathrm{kg})$ & 0.16 & 0.16 & 0.16 & 0.16 & $0.66 \pm 0.21$ \\
\hline Gr-IX & Diabetic+(Resv10 mg/kg+Met 250 mg/kg) & 0 & 0.16 & 0.16 & 0.16 & $0.50 \pm 0.22$ \\
\hline
\end{tabular}

Resv-resveratrol, Met- metformin.

\section{To assess chemical allodynia}

Table 4 showed that mean score is significantly increased in disease control $(2.8 \pm 0.17,1.83 \pm 0.17)$ in comparison to
HFD control $(0.33 \pm 0.21)$ as well as normal control $(0.17 \pm 0.17)$ at both the time interval of 30 and 60 minutes. Group that received resveratrol $20 \mathrm{mg} / \mathrm{kg}$ produced significant decrease in mean score $(0.5 \pm 0.21)$ 
which is similar with metformin $(0.16 \pm 0.17)$ treated group and not significantly different from normal control at 30 min interval in comparison to disease control. But at 60 min interval only metformin treated group $(0.17 \pm 0.17)$ produced significant decrease in mean score whereas resveratrol 10 and 20 produced decrease in the mean score but is not statistically significant in comparison to disease control.

Table 4: Effect of drugs on mean score in formalin test in diabetic rats at 4 weeks $(n=6)$.

\begin{tabular}{|llll|}
\hline \multirow{2}{*}{ Groups } & \multicolumn{3}{l}{ Mean score } \\
\hline Gr-II & Control (DMSO) & $0.17 \pm 0.17$ & $0.17 \pm 0.17$ \\
\hline Gr-III & $\begin{array}{l}\text { HFD } \\
\text { control+DMSO }\end{array}$ & $0.33 \pm 0.21$ & $0.33 \pm 0.21$ \\
\hline \multirow{3}{*}{ Gr-IV } & $\begin{array}{l}\text { DC (HFD+STZ- } \\
40 \mathrm{mg} / \mathrm{kg})+\end{array}$ & $2.8 \pm 0.17^{* \$}$ & $1.83 \pm 0.17^{* \$}$ \\
& DMSO & & \\
\hline Gr-V & $\begin{array}{l}\text { Diabetic+Resv }(5 \\
\mathrm{mg} / \mathrm{kg})\end{array}$ & $2.3 \pm 0.21$ & $1.67 \pm 0.21$ \\
\hline Gr-VI & $\begin{array}{l}\text { Diabetic+Resv } \\
(10 \mathrm{mg} / \mathrm{kg})\end{array}$ & $1.16 \pm 0.17$ & $1 \pm 0.26$ \\
\hline Gr-VII & $\begin{array}{l}\text { Diabetic+Resv } \\
(20 \mathrm{mg} / \mathrm{kg})\end{array}$ & $0.5 \pm 0.21^{\#}$ & $0.33 \pm 0.21$ \\
\hline Gr-VIII & $\begin{array}{l}\text { Diabetic+Met } \\
(500 \mathrm{mg} / \mathrm{kg})\end{array}$ & $0.16 \pm 0.17^{\#}$ & $0.17 \pm 0.17^{\#}$ \\
\hline Gr-IX & $\begin{array}{l}\text { Diabetic+(Resv } \\
10 \mathrm{mg} / \mathrm{kg}+\mathrm{Met} \\
250 \mathrm{mg} / \mathrm{kg})\end{array}$ & $0.33 \pm 0.21^{\#}$ & $0.17 \pm 0.17^{\#}$ \\
\hline
\end{tabular}

Data expressed as mean \pm SEM, Resv-resveratrol, Metmetformin, ${ }^{*} \mathrm{p}<0.05$ (control vs. diabetic group), $\$ \mathrm{p}<0.05$ (HFD vs. DC), ${ }^{\#} \mathrm{p}<0.05$ (diabetic group vs. treatment groups).

Table 5: Effect of drugs on charcoal meal test in diabetic rats.

\begin{tabular}{|lll|}
\hline Gr-II & Control (DMSO) & $\begin{array}{l}\text { Gastrointestinal } \\
\text { transit }(\%)\end{array}$ \\
\hline Gr-III & HFD control + DMSO & $61.03 \pm 0.47$ \\
\hline Gr-IV & $\begin{array}{l}\text { DC (HFD+STZ-40 } \\
\mathrm{mg} / \mathrm{kg})\end{array}$ & $28.17 \pm 0.98^{*}$ \\
\hline Gr-V & $\begin{array}{l}\text { Diabetic+Resv }(5 \\
\mathrm{mg} / \mathrm{kg})\end{array}$ & $27.58 \pm 0.99$ \\
\hline Gr-VI & $\begin{array}{l}\text { Diabetic+Resv }(10 \\
\mathrm{mg} / \mathrm{kg})\end{array}$ & $41.63 \pm 0.81 \#$ \\
\hline Gr-VII & $\begin{array}{l}\text { Diabetic+Resv }(20 \\
\mathrm{mg} / \mathrm{kg})\end{array}$ & $52.17 \pm 0.37 \#$ \\
\hline Gr-VIII & $\begin{array}{l}\text { Diabetic+Met }(500 \\
\mathrm{mg} / \mathrm{kg})\end{array}$ & $60.15 \pm 1.37 \#$ \\
\hline Gr-IX & $\begin{array}{l}\text { Diabetic +(Resv } 10 \\
\mathrm{mg} / \mathrm{kg}+\text { Met } 250 \\
\mathrm{mg} / \mathrm{kg})\end{array}$ & $55.40 \pm 1.79 \#$ \\
\hline & F value & 191.3 \\
\hline
\end{tabular}

Data expressed as mean \pm SEM, Resv-resveratrol, Metmetformin, $* \mathrm{p}<0.05$ (control vs. diabetic group), $\$ \mathrm{p}<0.05$ (HFD vs DC), ${ }^{\#}<0.05$ (diabetic group vs. treatment groups).

\section{Functional biomarkers}

It was observed from Table 5, that gastrointestinal transit $(\%)$ is significantly decreased in disease control $(28.17 \pm 0.98 \%)$ in comparison with normal control $(61.03 \pm 0.47 \%)$ as well as in HFD $(61.28 \pm 0.65 \%)$. Groups received resveratrol at a dose of 10 and $20 \mathrm{mg} / \mathrm{kg}$ produced significant increase in the gastrointestinal (GI) transit percentage $(41.63 \pm 0.81$ and $52.17 \pm 0.37 \%)$ which is similar to metformin $(60.15 \pm 1.37 \%)$ and not significantly different from normal control.

\section{DISCUSSION}

This study has been undertaken to evaluate the effect of resveratrol on diabetic neuropathy in HFD and low dose STZ (40 mg/kg) model of type 2 DM in wistar albino rats. The effect resveratrol in different doses like 5, 10 and 20 $\mathrm{mg} / \mathrm{kg}$, were studied by estimating biochemical parameters (FPG, lipid profile) in plasma, behavioral biomarkers of neuropathy (tail flick latency using tail immersion test, acetone induced cold allodynia, chemical allodynia using formalin test) and functional biomarker of autonomic neuropathy using charcoal meal test. The results were compared with that of standard drug (metformin). Wistar albino rats are selected for the study as they are standardized experimental animals and streptozotocin induces diabetes in experimental animals showing significantly higher FPG and lipid abnormalities. $^{18}$

To mimic type $2 \mathrm{DM}$, a single low dose of STZ at 40 $\mathrm{mg} / \mathrm{kg}$ body weight was injected after 2 weeks of HFD feeding. High doses of STZ (>40 mg/ $\mathrm{kg}$ body weight) is well known to be taken by pancreatic $\beta$-cells via GLUT2 and to induce severe damages of pancreatic $\beta$-cells, mimicking type $1 \mathrm{DM} .{ }^{19}$ But the combination of HFD and low doses of STZ resulted in characteristic of type $2 \mathrm{DM}$ where insulin resistance plays a major role in pathophysiology leading to various metabolic alterations like increased blood glucose level, hyperinsulinemia, and dyslipidemia. ${ }^{20}$ So in this present study HFD or low dose STZ model was selected. This model was also based on the principle that an increased level of blood sugar, dyslipidemia, derangement of oxidative stress parameter in a diabetic rat lead to development of neuropathy. This condition is characterized by altered pain threshold (hyperalgesia, hypoalgesia and allodynia) due to the hyperactivity / inactivation of nociceptive ' $C$ ' fibers and other mechanisms and gastroparesis due to autonomic neuropathy. These characteristics were assessed by observing behavioral and functional biomarkers of DN in this model. ${ }^{21}$

Early treatment with antidiabetic dugs and lifestyle modification are often recommended for prevention and control of diabetes and its complications. Though there are a good number of drugs available to control the disease but most of them are not free from lethal unwanted effects. Thus, there has been a growing interest 
in pharmaceutical products with the least side effects and the maximal preventive outcome. ${ }^{22}$ Resveratrol which is used as nutritional supplements has been reported in several studies to possess antihyperglycemic, beneficial effect on lipid profile. ${ }^{8}$ It also prevents development of various complications. So the present study was undertaken to evaluate the effects of resveratrol to know whether it has got any beneficial effects on type 2 DM and can prevent development of diabetic neuropathy or not.

In this study vehicles used like distilled water and DMSO didn't produce any change in biochemical parameters.

\section{Effect on FPG level}

DC group received HFD or STZ produced significant increase in plasma glucose level in this present study. ${ }^{20}$ Resveratrol treated groups in doses 10 and $20 \mathrm{mg} / \mathrm{kg}$ for a period of 14 days produced significant decrease in FPG in comparison to disease control which was consistent with Jung et al study. ${ }^{20}$ This effect is similar to standard drug metformin. The combined effect of resveratrol with metformin showed significant decrease in plasma glucose level which is comparable with normal control group. ${ }^{23}$

\section{Effect on lipid profile}

Resveratrol in doses 10 and $20 \mathrm{mg} / \mathrm{kg}$ produced significant decrease in TC, TG and LDL level with increase in HDL level in a dose dependent manner in comparison to disease DC which showed beneficial effect on dyslipidemia due to diabetes. Result of the present study corroborates with observations made by Shahi et al. ${ }^{24}$ Also metformin alone as well as in combination with resveratrol showed significant improvement in plasma lipid profile in diabetic rats, comparable with normal control.

\section{Effect on neuropathic pain}

\section{Effect on thermal test}

At 4 weeks of induction of diabetes, the DC group showed significant decrease in pain threshold to hot (tail flick latency) and cold form of nociception (acetone induced cold allodynia) as indicated by tail immersion test and acetone paw test respectively. The pain produced, is due to hyperalgesia in tail immersion test (hot) whereas allodynia occured in case of acetone paw test. These characteristics are may be due to altered sensory processing is developed in case of diabetic neuropathy to mild nocifensive responses (hyperalgesia) and to normally non-painful stimuli (allodynia). ${ }^{25}$ Pretreatment with resveratrol in doses (10 and $20 \mathrm{mg} / \mathrm{kg})$ produced significant increase in pain threshold in comparison to DC which corroborates with Sharma et al. ${ }^{26}$ Result showed resveratrol's protective effect against DN.
Metformin alone as well as in combination with resveratrol showed significant protection against pain behavior.

At 6 weeks after induction of diabetes, hypoalgesia developed leading to significant increase in TFL. This development of hypoalgesia may be the result of nerve damage due to DM. Resveratrol at dose of $20 \mathrm{mg} / \mathrm{kg}$ showed significant change in TFL in comparison to diabetic group and is comparable to that of normal control. ${ }^{27}$ In paw acetone test similarly due to hypoalgesia cumulative score is not significantly different in disease control compared with normal control. Groups received standard and test drugs also did not produced any significant change in cumulative score than that of disease control. This effect is similar to that of normal control.

\section{Effect on chemical test}

This study was conducted once only considering persistent nature of tissue damage by formalin. At 4 weeks of induction of diabetes, the disease control group showed significant decrease in pain threshold at both the time intervals (30 and 60 mins) of late tonic phase (15-60 mins) which may be due to role of neurotransmitters such as spinal prostaglandin in tonic phase in diabetic neuropathy. ${ }^{25}$ Pretreatment with resveratrol in doses (10 and $20 \mathrm{mg} / \mathrm{kg}$ ) produced increase in pain threshold in comparison to disease control. Metformin alone as well as combination with resveratrol showed significant protection against pain behaviour in comparison to disease control which is comparable with normal control group.

\section{Effect on autonomic neuropathy}

At 8 weeks, it is observed that gastrointestinal transit (\%) is significantly decreased in DC in comparison with normal control which showed the development of gastroparesis due to autonomic neuropathy associated with prolonged untreated type $2 \mathrm{DM}^{28}$ Resveratrol pretreated group at 10 and $20 \mathrm{mg} / \mathrm{kg}$ doses produced significant increase in GI transit percentage compared with that of DC which is similar to metformin treated group and not significantly different from normal control showing prevention of autonomic neuropathy.

So results show the prevention of behavioral and functional biomarkers of neuropathy, corroborates with Kumar et al. ${ }^{23}$

\section{CONCLUSION}

Predisposing factors for development of DN in type $2 \mathrm{DM}$ are hyperglycemia, insulin resistance, dyslipidemia and oxidative stresses. Resveratrol at a dose of 10 and 20 $\mathrm{mg} / \mathrm{kg}$ and combination with metformin produced significant protection against development of neuropathy in this study due to its better control over the predisposing factors. Basing on this evidence it can be concluded that 
test drug (resveratrol) itself and its combination with other antidiabetic drug can be evaluated to control blood glucose in type $2 \mathrm{DM}$ and for preventive therapy in patient at risk of developing complications like DN. By this the dose of antidiabetic agent can be reduced and may limit the incidence of adverse drug reaction because of particular drug. Therefore it can be suggested to consider test drug for more and more animal studies and further clinical trials to establish its clinical use in future.

\section{Funding: No funding sources}

Conflict of interest: None declared

Ethical approval: The study was approved by the Institutional Ethics Committee

\section{REFERENCES}

1. Ogurtsova K, da Rocha Fernandes JD, Huang Y, Linnenkamp U, Guariguata L, Cho NH, et al. IDF Diabetes Atlas: Global estimates for the prevalence of diabetes for 2015 and 2040. Diabetes Res Clin Pract. 2017;128:40-50.

2. Gill HK, Yadav SB, Ramesh V, Bhatia E. A prospective study of prevalence and association of peripheral neuropathy in Indian patients with newly diagnosed type 2 diabetes mellitus. J Postgrad Med. 2014;60:270-5.

3. Moxey PW, Gogalniceanu P, Hinchliffe RJ, Loftus IM, Jones KJ, Thompson MM, et al. Lower extremity amputations - a review of global variability in incidence. Diabetic Med. 2011;28:(10)1144-53.

4. Wilson JR, Stittsworth JD Jr, Kadir A, Fisher MA. Conduction velocity versus amplitude analysis: Evidence for demyelination in diabetic neuropathy. Muscle Nerve. 1998;21:1228-30.

5. Heubeck E. New Treatment Options for Diabetic Neuropathy. DOC NEWS. 2006;3(2);8-9.

6. Modak M, Dixit P, Londhe J, Ghaskadbi S, Paul TA. Devasagayam. Indian Herbs and Herbal Drugs Used for the Treatment of Diabetes, J Clin Biochem Nutr. 2007;40(3):163-73.

7. Jalili C, Roshankhah S, Moradi Y, Salahshoor MR. Resveratrol attenuates malathion-induced renal damage by declining oxidative stress in rats. Int $\mathbf{J}$ Pharma Investig. 2018;8:192-9.

8. Su HC, Hung LM, Chen JK. Resveratrol, a red wine antioxidant, possesses an insulin-like effect in streptozotocin-induced diabetic rats. Am J Physiol Endocrinol Metab. 2006;290(6):E1339-46.

9. Buettner R, Parhofer KG, Woenckhaus M, Wrede CE, Kunz-Schughart LA, Schölmerich J, et al. Defining high-fat-diet rat models: metabolic and molecular effects of different fat types. J Mol Endocrinol. 2006;36(3):485-501.

10. Rivera L, Mor'on R, Zarzuelo A, Galisteo M. Longterm resveratrol administration reduces metabolic disturbances and lowers blood pressure in obese Zucker rats. Biochem Pharmacol. 2009;77(6):105363.

11. Chang KJ. Effect of taurine and beta alanine on morphological changes of pancreas in streptozotocin induced diabetic rats. Adv Exp Med Biol. 2000;483:571-7.

12. Lu HE, Jian CH, Chen SF, Chen TM. Hypoglycaemic effects of fermented mycelium of Paecilomyces farinosus (G30801) on high-fat fed rats with streptozotocin-induced diabetes, Indian J Med Res. 2010;131:696-701.

13. Friedewald WT, Levy RI, Frederickson DS. Estimation of the concentration of low density lipoprotein cholesterol in plasma, without use of preparative ultracentrifuge. Clin Chem. 1972;18:499502.

14. Kawakita K, Funakoshi M. A quantitative study on the tail flick test in rat. Physiol Behav. 1987;39(2):235-40.

15. Bardin L, Malfetes N, Newman-Tancredi A, Depoortre R. Chronic restraint stress induces mechanical and cold allodynia and enhances inflammatory pain in rat: Relevance to human stress associated painful pathologies. Behavioural Brain Res. 2009;205:360-6.

16. Abbott FV, Franklin KBJ, Westbrook RF. The formalin test: scoring properties of the first and second phases of the pain responses in rats. Pain. 1995;60:91-102.

17. Bijender S, Harish D, Rishi S, Patil BM. Effect of vitamin $\mathrm{E}$ on the impaired gastrointestinal activity of streptozotocin induced diabetic rats. IJP. 2003;35:186-7.

18. Rodrigues B, Kong MCCJ, Goyal RK, McNeil JH, Strain differences in susceptibility to streptozotocininduced diabetes: effects on hypertriglyceridemia and cardiomyopathy. Cardiovascular Res. 1997;34(1):199-205.

19. Szkudelski T. The mechanism of alloxan or streptozotocin action in B cells of the rat pancreas. Physiol Res. 2001;50(6):537-46.

20. Jung JY, Lim Y, Moon MS, Kim JY, Kwon O. Onion peel extracts ameliorate hyperglycemia and insulin resistance in high fat diet/streptozotocin induced diabetic rats. Nutr Metab (Lond). 2011;8:18.

21. Kumar NP, Annamalai AR, Thakur RS. Antinociceptive property of Emblica officinalis Gaertn (Amla) in high fat diet-fed/low dose streptozotocin induced diabetic neuropathy in rats. Indian J Exp Biol. 2009;47(9):737-42.

22. Pradeepa R, Rema M, Vignesh J, Deepa M, Deepa R, Mohan V. Prevalence and risk factors for diabetic neuropathy in an urban south Indian population: The Chennai Urban Rural Epidemiology Study (CURES55). Diabet Med. 2008;25:407-12.

23. U.K. Prospective Diabetes Study Group. Eeffect of intensive blood glucose-control with metformin on complications in overweight patients with type 2 diabetes (UKPDS). Lancet. 1998;352:854-65.

24. Shahi MM, Haidari F, Shiri MR. Comparison of effect of resveratrol and vanadium on diabetes related dyslipidemia and hyperglycemia in streptozotocin induced diabetic rats. Adv Pharma Bulletin. 2011;1(2):81-6. 
25. Freshwater JD, Svensson CI, Malmberg AB, Calcutt NA. Elevated spinal cyclooxygenase and prostaglandin release during hyperalgesia in diabetic rats. Diabetes. 2002;51(7):2249-55.

26. Sharma S, Kulkarni SK, Chopra K. Effect of resveratrol, a polyphenolic phytoalexin, on thermal hyperalgesia in a mouse model of diabetic neuropathic pain. Fundam Clin Pharmacol. 2007;21(1):89-94.

27. Kumar A, Kaundal RK, Iyer S, Sharma SS. Effects of resveratrol on nerve functions, oxidative stress and
DNA fragmentation in experimental diabetic neuropathy. Life Sci. 2007;80(13):1236-44.

28. Koch KL, Calles-Escandón J. Diabetic gastroparesis. Gastroenterol Clin North Am. 2015;44(1):39-57.

Cite this article as: Das S, Behera JP, Rojaramani Y, Mohanty RR. Effect of resveratrol on diabetic neuropathy in wistar albino rats. Int J Basic Clin Pharmacol 2020;9:16-23. 